\title{
A prospective study on the efficacy of Pipelle biopsy to diagnose endometrial pathology in patients with abnormal uterine bleeding
}

\author{
Sunitha Mary Mathew ${ }^{1 *}$, Pramod Thomas $^{2}$
}

\begin{abstract}
${ }^{1}$ Department of Obstetrics and Gynecology, Believers Church Medical College, Hospital, Tiruvalla, Kerala, India ${ }^{2}$ Department of Community Medicine, Believers Church Medical College, Hospital, Tiruvalla, Kerala, India
\end{abstract}

Received: 24 September 2019

Accepted: 05 October 2019

\section{*Correspondence:}

Dr. Sunitha Mary Mathew,

E-mail: drsunithammathew@gmail.com

Copyright: () the author(s), publisher and licensee Medip Academy. This is an open-access article distributed under the terms of the Creative Commons Attribution Non-Commercial License, which permits unrestricted non-commercial use, distribution, and reproduction in any medium, provided the original work is properly cited.

\begin{abstract}
Background: Abnormal uterine bleeding is one of the most common problem encountered in gynaecology clinics. Assessment of endometrial pathology is recommended to rule out malignancy and premalignant conditions. Endometrial sampling can be done by Pipelle biopsy in outpatient units as well as by conventional dilatation and curettage in an operation theatre setup. Our study aims to find out the efficacy of office endometrial biopsy in terms of its sample adequacy, diagnostic accuracy and patient acceptability.

Methods: 120 women presenting with abnormal uterine bleeding were included. A detailed history along with clinical examination findings are entered in the proforma. Ultrasound scan was done for all of them to identify pelvic pathology and endometrial thickness. Endometrial sampling was then done with Pipelle without anaesthesia. Histopathology reports are collected and sample adequacy and pattern were analysed. Patients are subsequently followed up for a period up to one year. Those who underwent hysterectomy are analysed for the endometrial pathology in hysterectomy specimen which is used as gold standard and compared with Pipelle endometrial sampling histopathology.

Results: Sample adequacy for Pipelle biopsy was found to be $96 \%$. Diagnostic accuracy for atypical hyperplasia and adenocarcinoma is $92.5 \%$ and $94 \%$ respectively. In hysterectomy specimens, carcinoma endometrium coexisted with atypical hyperplasia in $40 \%$ of cases with atypical hyperplasia in pipelle biopsy report.

Conclusions: Thus, Pipelle endometrial biopsy is a cost-effective method for endometrial sampling except for focal lesions.
\end{abstract}

Keywords: Abnormal uterine bleeding, Endometrial hyperplasia, Endometrial carcinoma, Pipelle endometrial biopsy, Postmenopausal bleeding

\section{INTRODUCTION}

Abnormal uterine bleeding (AUB) is one of the most common problem encountered in gynaecology clinics causing huge impact on women's quality of life with a reported incidence of $14 \%$ to $25 \%$ among women of reproductive age group. ${ }^{1}$ Descriptive terms used to categorise AUB pattern include heavy menstrual bleeding, intermenstrual bleeding, post-menopausal bleeding, polymenorrhea and irregular bleeding pattern. According to PLAM-COIEN classification of AUB introduced by FIGO the aetiology of AUB is classified into structural and non-structural causes. ACOG recommends endometrial biopsy for women with AUB older than 45 year as first line test and in younger women with history of unopposed oestrogen exposure (such as obesity, and PCOS), failed medical management and persistent AUB. ${ }^{2}$ Sampling of endometrium can be done 
by conventional dilatation and cutterage and also by office endometrial biopsy devices like Pipelle, Vabra aspirator etc. The latter can be done in outpatient department without any anaesthesia and at a comparatively lower cost. The literatures show a sample adequacy rate of $89.74 \%$ to $98 \%$ for Pipelle biopsy when compared with D and C. ${ }^{3}$ Moreover in $60 \%$ of D and C less than half of the endometrium is curetted with added risk of anaesthesia complications, perforation and infections.

Endometrial carcinoma is one of the leading malignancy among women and its incidence is increasing along with its risk factors like obesity, diabetes and PCOS. Diagnosing endometrial hyperplasia, a premalignant condition for carcinoma endometrium helps to reduce the morbidity of carcinoma endometrium. Pipelle has found to have nearly $100 \%$ negative predictive value for endometrial carcinoma and hyperplasia. ${ }^{4}$

Our study was done to analyse the cost effectiveness of Pipelle biopsy as still many clinicians rely on dilatation and curettage doubting sample adequacy of Pipelle endometrial biopsy. In this study the sampling accuracy of Pipelle endometrial biopsy is compared with the gold standard as hysterectomy specimen.

\section{METHODS}

This prospective cohort study was conducted at Believers Church Medical College Hospital, Tiruvalla, Kerala with due ethical permission from institutional ethical committee. Women $(n=120)$ who presented to our gynaecology OPD during the period June 2017 to June 2018 with abnormal uterine bleeding were included in this study after obtaining the written informed consent. The proforma included details like age, parity, mode of delivery, ultrasound report with endometrial thickness. A detailed history about bleeding pattern, duration and examination findings are entered in the proforma. Ultrasound scan was done for all of them to identify pelvic pathology and endometrial thickness and also to rule out focal lesions. Patient is placed in dorsal position with foot supported on foot rest, and bimanual examination is done to assess size and position of uterus. The cervix is then held with vulsellum after cleaning followed by uterine sound examination. Endometrial sampling was then done with pipelle without anaesthesia and after explaining the procedure. An Endometrial cannula with a length of $23 \mathrm{~cm}$, inner diameter of $2.6 \mathrm{~mm}$ and outer diameter of $3.1 \mathrm{~mm}$ and a blunt distal tip is used for this procedure. The endometrial tissue is obtained by suction aspiration from all walls of uterus by rotating the device 3 to 4 times to ensure adequate specimen collection. Patient acceptability and pain tolerance was assessed by need for analgesics (Mild: no need for analgesics;Moderate:need oral analgesics;Severe:need parentral analgesics or admission). The specimen is sent in formalin bottles to pathology department. Histopathology report is collected and sample size, adequacy and histologic patterns are evaluated. Patients are subsequently followed up for a period of up to one year. Those who underwent hysterectomy are further analysed for the endometrial pathology in hysterectomy specimen which is compared with their Pipelle endometrial sampling histopathology. Among the 120 patients, 67 underwent subsequent hysterectomy for AUB due to the inclusion of women with fibroid uterus, adenomyosis, endometriosis, suspected malignancy, AUB with thickened endometrium in our study.

\section{Inclusion criteria}

- Woman above 35 years with AUB

- Ultrasound findings suggestive of fibroids, adenomyosis, endometriosis and malignancy

- Endometrial thickness above $12 \mathrm{~mm}$ in perimenopausal if there is no other pelvic pathology in USG.

- All postmenopausal bleeding irrespective of endometrial thickness.

\section{Exclusion criteria}

- Pregnancy

- Bleeding due to cervical or vaginal pathology

- AUB due to coagulopathy, drugs and endocrine causes

- Genital tract infections and PID.

\section{Statistical analysis}

Pipelle biopsy report and subsequent endometrial histopathology in hysterectomy samples were analysed using diagnostic tests and further using Fisher's exact test. The accuracy was calculated and expressed as percentage with $95 \%$ confidence interval. SPSS version 20 was used for statistical analysis. A p-value less than 0.05 was considered as significant.

\section{RESULTS}

Majority of the women were of the age group 45-49 years (41 patients, 34\%), followed by the group 40-44 years (25\%). Thus $59 \%$ of women belongs to the age group of 40-49 years. $12.5 \%$ of women were above 60 years. Oldest being a 78-year-old lady with recurrent Postmenopausal bleeding and negative Pipelle biopsy and it was a benign submucosal fibroid in subsequent hysterectomy (Table 1).

\section{Bleeding pattern in $A U B$}

Heavy menstrual bleeding (HMB) was the most common bleeding pattern with an incidence of $66 \%$ followed by postmenopausal bleeding (PMB) with incidence of $19 \%$. $5.8 \%$ presented with Intermenstrual bleeding (IMB). Polymenorrhagia was seen among $5 \%$ of women and 
$3.3 \%$ belonged to miscellaneous group with irregular bleeding and continuous bleeding (Figure 1).

Table 1: Age distribution of study population.

\begin{tabular}{|ll|}
\hline Age in years & Frequency $(\%)$ \\
\hline $35-39$ & $7(5.8 \%)$ \\
\hline $40-44$ & $30(25 \%)$ \\
\hline $45-49$ & $41(34 \%)$ \\
\hline $50-54$ & $19(15 \%)$ \\
\hline$>55-59$ & $8(6.6 \%)$ \\
\hline$>60$ & $15(12.5 \%)$ \\
\hline
\end{tabular}

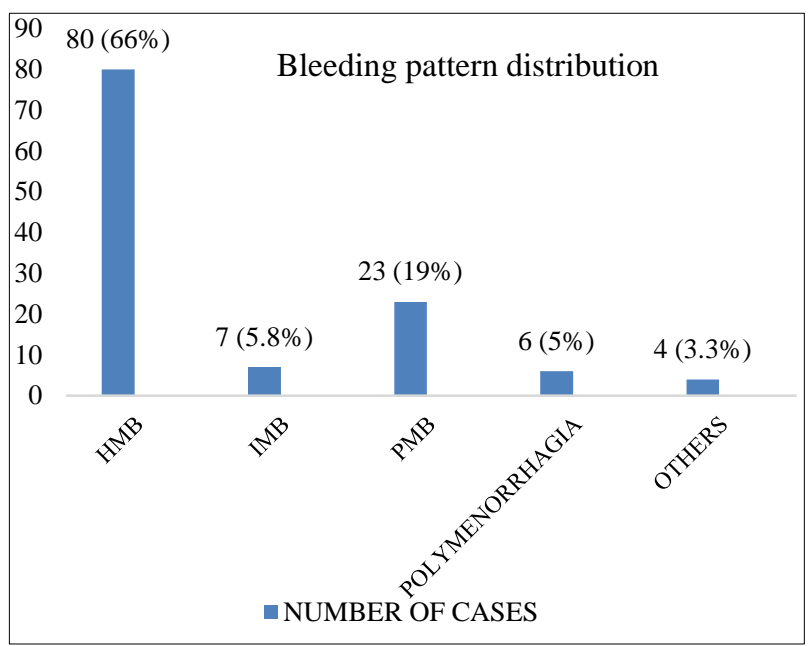

HMB: heavy menstrual bleeding, IMB: intermenstrual bleeding, PMB: postmenopausal bleeding.

\section{Figure 1: Bleeding pattern distribution.}

\section{Sample adequacy in Pipelle biopsy report}

Out of the 120 samples, 115 cases had adequate sample tissue. Thus, sample adequacy in our study was $96 \% .4 \%$ (5 cases) were inadequate samples. On analysing the inadequate samples, three were taken from thin endometrium in postmenopausal bleeding and histopathological report were just blood clots, fragmented scanty glands and senile cystic atrophic changes respectively. Two cases of recurrent postmenopausal bleeding with negative Pipelle biopsy (inadequate samples) were found to have sub mucosal fibroid and endometrial polyp in their subsequent hysterectomy specimen. Thus, focal lesions can be missed in Pipelle biopsy (Figure 2).

The 107 patients needed no analgesics and had only tolerable pain. ${ }^{10}$ Patients needed oral analgesics. Only (3 patients) $2.5 \%$ of the study population needed IV sedation or analgesics.

The most common histopathological pattern was proliferative endometrium, 38 cases $(31.6 \%)$. This was followed by secretory endometrium, 20.8\%. Closely followed by disordered proliferative endometrium, $15 \%$. Hyperplasia without atypia was seen in $7.5 \%$ of cases and atypical hyperplasia in $8 \%$ of cases. $3 \%$ had adenocarcinoma and 3\% had endometrial polyp (Table 2).

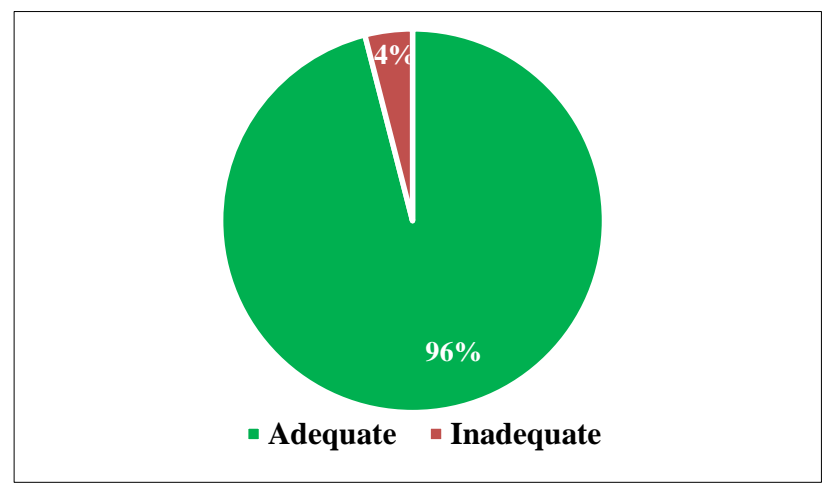

Figure 2: Sample adequacy in Pipelle biopsy reports.

Table 2: Histopathology pattern in Pipelle biopsy.

\begin{tabular}{|c|c|c|}
\hline Endometrial pattern & $\begin{array}{l}\text { number of } \\
\text { cases }(n=120)\end{array}$ & Percentage \\
\hline Proliferative endometrium & 38 & $31.6 \%$ \\
\hline Secretory endometrium & 25 & $20.8 \%$ \\
\hline $\begin{array}{l}\text { Hormonally modified } \\
\text { endometrium }\end{array}$ & 7 & $5 \%$ \\
\hline $\begin{array}{l}\text { Disordered proliferative } \\
\text { endometrium }\end{array}$ & 18 & $15 \%$ \\
\hline Inadequate biopsy & 5 & $4.1 \%$ \\
\hline Hyperplasia without atypia & 9 & $7.5 \%$ \\
\hline Atypical hyperplasia & 10 & $8.3 \%$ \\
\hline Adenocarcinoma & 4 & $3 \%$ \\
\hline Endometrial polyp & 4 & $3 \%$ \\
\hline
\end{tabular}

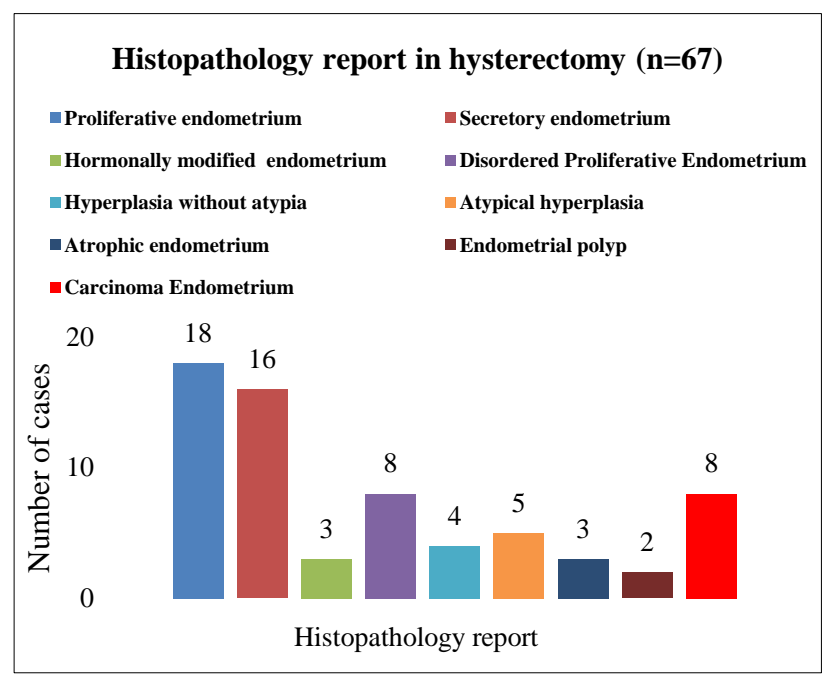

Figure 3: Histopathology report in hysterectomy specimen.

\section{Subsequent hysterectomy}

A 67 of the 120 patients underwent subsequent hysterectomy for AUB. Our inclusion criteria included 
women with fibroid uterus, adenomyosis, endometriosis, suspected malignancy, AUB with thickened endometrium and hence a majority of them were for subsequent hysterectomy. HPE pattern of the hysterectomy was analysed and proliferative was the most common one as in the Pipelle biopsy group with incidence of $26.8 \%$ closely followed by secretory endometrium. There were 8 cases of carcinoma endometrium $(11.9 \%)$.

Table 3: Comparison of histopathological report of Pipelle biopsy and hysterectomy.

\begin{tabular}{|lll|}
\hline HPE Report & Pipelle biopsy $(\mathbf{n = 1 2 0}), \mathbf{n}(\mathbf{\%})$ & Hysterctomy $(\mathbf{n = 6 7}), \mathbf{n}(\%)$ \\
\hline Proliferative endometrium & $38(31.6)$ & $18(26.8 \%)$ \\
\hline Secretory endometrium & $25(20.8)$ & $16(23.8 \%)$ \\
\hline Hormonally modified endometrium & $7(5)$ & $3(4.5 \%)$ \\
\hline Disordered proliferative endometrium & $18(15)$ & $4(11.9 \%)$ \\
\hline Hyperplasia without atypia & $9(7.5)$ & $5(7.4 \%)$ \\
\hline Atypical hyperplasia & $10(8.3)$ & $3(4.5 \%)$ \\
\hline Atrophic endometrium & - & $8(11.9 \%)$ \\
\hline Carcinoma endometrium & $4(3)$ & $2(2.9 \%)$ \\
\hline Endometrial polyp & $4(3)$ & - \\
\hline Inadequate biopsy & $5(4.1)$ & $\mathbf{6 7}(\mathbf{1 0 0})$ \\
\hline Total & $\mathbf{1 2 0}(\mathbf{1 0 0})$ & \\
\hline
\end{tabular}

\section{Analysis of disordered proliferative endometrium in Pipelle}

There were 18 cases of disordered proliferative endometrium in pipelle biopsy out of which 9 patients underwent hysterectomy. Among the 9, 5 patients had hormonally modified endometrium in hysterectomy specimen, 2 patients had secretory endometrium and another 2 had hyperplasia without atypia. Even though majority of cases turned out to be hormonally modified endometrium, it can also progress to simple endometrial hyperplasia, so follow up is advisable especially in perimenopausal and postmenopausal ladies.

\section{Analysis of hyperplasia without atypia}

There were nine cases of hyperplasia without atypia in Pipelle biopsy out of which 4 had hysterectomy. In subsequent report 2 had hyperplasia without atypia, one patient had secretory endometrium and another one had hormonally modified endometrium.

Table 4: Statistical analysis of endometrial HPE report by Pipelle biopsy.

\begin{tabular}{|llllll|}
\hline HIPE Report & Sensitivity (\%) & Specificity (\%) & PPV & NPV & Accuracy $(\%)$ \\
\hline Proliferative endometrium & 66.6 & 93.9 & 80 & 88.5 & 86.6 \\
\hline Secretory endometrium & 81.3 & 88.2 & 68.4 & 93.8 & 86.6 \\
\hline SEH & 50 & 96.8 & 50 & 96.8 & 94.0 \\
\hline Atypical hyperplasia & 100 & 91.9 & 50 & 100 & 92.5 \\
\hline Hyperplasia (total) & 77.8 & 88 & 50 & 96.2 & 86.6 \\
\hline Adenocarcinoma & 50 & 100 & 100 & 93.6 & 94.0 \\
\hline
\end{tabular}

HPE: Histopathological report, SEH: Simple endometrial hyperplasia or hyperplasia without atypia, PPV: Positive predictive value, NPV: Negative predictive value.

\section{Atypical hyerplasia and carcinoma endometrium}

All ten patients with atypical hyperplasia underwent hysterectomy. On analysis four patients had carcinoma endometrium stage IA, 5 had atypical hyperplasia and one had disordered proliferative endometrium endometrium (Pipelle showed focal atypia). The incidence of carcinoma endometrium among this study population was $6.6 \%$. Risk of endometrial cancer in women with postmenopausal bleeding is $10 \%$ (ICMR). In our study 5 out of 23 cases of PMB had carcinoma Endometrium with an incidence of $21 \%$. Three women presented with HMB and were in the premenopausal group. 4 out of eight cases of carcinoma endometrium 
had atypical hyperplasia in Pipelle biopsy and other 4 had adenocarcinoma in Pipelle biopsy report.

\section{Statistical analysis of endometrial histopathology report by Pipelle biopsy}

Table 4 depicts the statistical analysis of endometrial pathology in which Pipelle biopsy had an accuracy of $86.6 \%$ for detecting proliferative endometrium and secretory endometrium. 94\% accuracy for hyperplasia without atypia, $92.5 \%$ for atypical hyperplasia, $86.6 \%$ for hyperplasia (total) and $94 \%$ for diagnosing carcinoma endometrium.

Pipelle biopsy had $100 \%$ specificity and PPV and $93.6 \%$ negative predictive value for diagnosing endometrial adenocarcinoma. The sensitivity for adenocarcinoma in our study was $50 \%$, this was because $50 \%$ of adenocarcinoma diagnosed in hysterectomy specimen had atypical hyperplasia in Pipelle and this is due to high coexistence $(40 \%)$ of atypical hyperplasia and early stage adenocarcinoma.

On analysing the validity of Pipelle biopsy for diagnosing endometrial hyperplasia and carcinoma by Fisher's Exact test the $\mathrm{p}$ value for both was $\mathrm{p}=0.0001$, and was statistically significant.

Table 5: Validity of Pipelle endometrial sampling for endometrial hyperplasia and endometrial carcinoma.

\begin{tabular}{|lll|}
\hline $\begin{array}{l}\text { Validity of } \\
\text { Pipelle }\end{array}$ & $\begin{array}{l}\text { Endometrial } \\
\text { hyperplasia }(\%)\end{array}$ & $\begin{array}{l}\text { Endometrial } \\
\text { carcinoma }(\%)\end{array}$ \\
\hline sensitivity & 77.8 & 50 \\
\hline specificity & 88.3 & 100 \\
\hline PPV & 50 & 100 \\
\hline NPV & 96.2 & 93.65 \\
\hline P-value & 0.0001 & 0.0001 \\
\hline
\end{tabular}

\section{DISCUSSION}

Abnormal uterine bleeding is one of the most common problem encountered in gynaecology clinics among women of reproductive age group. Majority of the women in our study were of the age group 45-49 year $(n=41,34 \%)$ followed by the group 40-44 years (30 cases). $59 \%$ of women $(n=71)$ belonged to age $40-49$ years. Thus, perimenopausal age group has highest incidence and this is similar to studies by Gopalan $U$ et al, $(54.7 \%)$ and Perween R et al. ${ }^{5,6}$

The bleeding pattern included heavy menstrual bleeding (HMB), inter menstrual bleeding (IMB), postmenopausal bleeding (PMB), polymenorrhagia and other such as irregular bleeding pervaginum. Heavy Menstrual Bleeding was the most common bleeding pattern with $66 \%$ of patient's presenting symptom. There were 23 cases of post-menopausal bleeding with incidence of $19 \%$. The incidence of postmenopaual bleeding is literature is $10 \%$ and 10 to $15 \%$ of women with postmenopausal bleeding can have carcinoma endometrium. $^{7}$ In more than $90 \%$ of postmenopausal women with endometrial carcinoma, PMB is the presenting symptom. ${ }^{8}$ Thus all cases of postmenpoausal bleeding must be promptly evaluated.

The sample adequacy in our study was $96 \%$. This goes in concordance with the study by Abdelazim IA et al who reported $97.9 \%$ adequacy rate. ${ }^{9}$ There were 5 cases with inadequate samples, 3 were postmenopausal bleeding with thin endometrium in USG and their histopathology report turned out to be blood clots, fragmented scanty glands and senile cystic atrophic changes respectively. Two cases of recurrent Postmenopausal bleeding with negative Pipelle biopsy (inadequate sample) were found to have sub mucosal fibroid and endometrial polyp in their subsequent hysterectomy specimen. Thus, focal lesions can be missed in pipelle biopsy. Transvaginal scan can detect focal lesion and is recommended for AUB evaluation.

Proliferative endometrium was the most common histopathological pattern ie. $31.6 \%$, similar results of $30.2 \%$ was seen in a study by Illavarasi et al. ${ }^{10}$ Disordered proliferative endometrium had incidence of $15 \%$ in our study. $11 \%$ of cases of disordered proliferative endometrium turned out to be hyperplasia without atypia in subsequent hysterectomy specimen, thus this pattern needs further follow up especially in premenopausal group.

The incidence of carcinoma endometrium among this study population was $6.6 \%$. 3\% of our Pipelle biopsy patients had carcinoma endometrium which is similar to the study by Singh P et al, $(2.6 \%)$ conducted at AIIMS jodhpur. ${ }^{11}$ Risk of endometrial cancer in women with postmenopausal bleeding is $10 \%$ (ICMR). In our study 5 out of 23 cases of PMB had carcinoma endometrium with an incidence of $21 \% .3$ women presented with HMB and were in the premenopausal group.

4 out of 10 cases of atypical hyperplasia (40\%) in Pipelle biopsy had carcinoma endometrium. Thus, our study reported an incidence of $40 \%$ and is similar to studies by Rahka E et al, which reported $37 \% .^{12}$ In a study by Byun $\mathrm{JM}$ et al, the rate of coexisting carcinoma endometrium in patients with atypical hyperplasia is $30.8 \% .{ }^{13}$ Moreover these rates increased to 40 to $48 \%$ in recent studies. As all these patients had grade 1 stage 1 carcinoma endometrium, they did not need any subsequent treatment. Thus, it is ideal for women with atypical hyperplasia to undergo hysterectomy rather than conservative management.

The validity of Pipelle endometrial biopsy was compared with studies by Sanam M et al, and Narice BF et al. ${ }^{14,15}$ Pipelle was found to have an accuracy of $92.5 \%$ and $94 \%$ in detecting atypical hyperplasia and carcinoma endometrium respectively in our study. Thus, Pipelle 
biopsy is a suitable cost-effective method for diagnosing endometrial pathology when combined with proper history and ultrasound examination.

\section{CONCLUSION}

- $\quad$ Pipelle endometrial biopsy is a well-tolerated method for analysing endometrial pathology with a sample adequacy of $96 \%$

- Detailed history, transvaginal ultrasound scan along with endometrial biopsy helps in proper diagnosis of AUB with good accuracy

- Disordered proliferative endometrium in perimenopausal and postmenopausal age group needs follow-up as it may progress to endometrial hyperplasia

- Due to high incidence of coexisting carcinoma endometrium in atypical hyperplasia surgical treatment is recommended

- Thus, Pipelle endometrial biopsy is a cost-effective method for endometrial sampling except for focal lesions.

Funding: No funding sources

Conflict of interest: None declared

Ethical approval: The study was approved by the Institutional Ethics Committee

\section{REFERENCES}

1. Fraser IS, Langham S, Uhl-Hochgraeber K. Healthrelated quality of life and economic burden of abnormal uterine bleeding. Expert Rev Obstet Gynecol. 2009;4:179-89.

2. Diagnosis of abnormal uterine bleeding in reproductive-aged women. Practice Bulletin No. 128. American College of Obstetricians and Gynecologists. Obstet Gynecol. 2012;120:197-206.

3. Rauf RSA, Sadia S, Waqar F, Zafar S, Sultana SWS. Outpatient endometrial biopsy with Pipelle vs diagnostic dilatation and curettage. J Ayub Med Coll Abbottabad. 2014;26(2):145-8.

4. Fakhar S, Saeed G, Khan AH, Alam AY. Validity of pipelle endometrial sampling in patients with abnormal uterine bleeding. Ann Saudi Med. 2008;28:188-9.

5. Gopalan U, Rajendiran S, Karnaboopathy R. Study of endometrial histopathology in women with abnormal uterine bleeding. Int J Reprod Contracept Obstet Gynecol. 2017;6(3):824-8.

6. Perween R, Alam SM, Karimi MA, Siddiqui SA. A clinicopathological study of abnormal uterine bleeding in peri and postmenopausal age group, with special emphasis on early diagnosis of uterine malignancy. Int J Contemp Med Res. 2016;3:867-72.

7. Timmermans A, Gerritse MB, Opmeer BC, Jansen FW, Mol BW, Veersema S. Diagnostic accuracy of endometrial thickness to exclude polyps in women with postmenopausal bleeding. J Clin Ultrasound. 2008;36:286-90.

8. Clarke MA, Long BJ, Del Mar Morillo A, Arbyn M, Bakkum-Gamez JN, Wentzensen N. Association of endometrial cancer risk with postmenopausal bleeding in women: a systematic review and metaanalysis. JAMA Intern Med. 2018;178(9):1210-22.

9. Abdelazim IA, Aboelezz A, Abdulkareem AF. Pipelle endometrial sampling versus conventional dilatation and curettage in patients with abnormal uterine bleeding. J Turk Ger Gynecol Assoc. 2013;14(1):1-5.

10. Ilavarsi CR, Joythi GS, Alva NK. Study of the efficacy of pipelle biopsy technique to diagnose endometrial disease in abnormal uterine bleeding. J Mid-life Health. 2019;10:75-80.

11. Singh P. Abnormal uterine bleeding- evaluation by endometrial aspiration. J Midlife Health. 2018;9(1):32-5.

12. Rakha E, Wong SC, Soomro I, Chaudry Z, Sharma A, Deen S, et al. Clinical outcome of atypical endometrial hyperplasia diagnosed on an endometrial biopsy: institutional experience and review of literature. Am J Surg Pathol. 2012;36:1683-90.

13. Byun JM, Jeong DH, Kim YN. Endometrial cancer arising from atypical complex hyperplasia: The significance in an endometrial biopsy and a diagnostic challenge. Obstet Gynecol Sci. 2015;58(6):468-74.

14. Sanam M, Majid MMK. Comparison the diagnostic value of dilatation and curettage versus endometrial biopsy by pipelle a clinical trial. Asian Pacific $\mathbf{J}$ Cancer Prevent. 2015;16(12):4971-5.

15. Narice BF, Delaney B, Dickson JM. Endometrial sampling in low-risk patients with abnormal uterine bleeding: a systematic review and meta-synthesis. BMC Fam Pract. 2018;19(1):135.

Cite this article as: Mathew SM, Thomas P. A prospective study on the efficacy of Pipelle biopsy to diagnose endometrial pathology in patients with abnormal uterine bleeding. Int J Reprod Contracept Obstet Gynecol 2019;8:4238-43. 